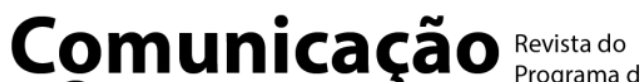

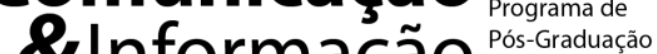 \&lnformação
}

\section{Matrizes Teóricas e Metodológicas da Produção Sobre Diversidade Cultural para Audiovisual no Intercom Nacional de 2005 a 2015}

\author{
Theoretical and Methodological Matrices of the Production on Cultural \\ Diversity For Audiovisual in the Intercom Nacional from 2005 to 2015

\section{Matrices Teóricas y Metodológicas de la Producción Sobre Diversidad Cultural para Audiovisuales en el Intercom Nacional de 2005 A 2015}

\author{
Livia Reginato David Viana ${ }^{l}$ \\ Vivianne Lindsay Cardoso ${ }^{2}$ \\ Juliano Maurício de Carvalho ${ }^{3}$ \\ João Guilherme da Costa Franco Silva D'Arcadia ${ }^{4}$
}

\begin{abstract}
Resumo: Este estudo é resultado de uma pesquisa de Iniciação Científica financiada pelo $\mathrm{CNPq}$ que teve como objetivo a identificação e sistematização de matrizes teóricas e metodológicas da produção intelectual brasileira sobre Diversidade Cultural nas Políticas Públicas de Comunicação para Audiovisual do período de dez anos (de 2005 a 2015). Adotou-se como metodologia a Revisão Integrativa. A amostra selecionada para análise foram os artigos encontrados nos anais do congresso nacional anual da Sociedade Brasileira de Estudos Interdisciplinares da Comunicação (Intercom). Os resultados apontaram os autores Néstor García Canclini e César Bolaño como os autores mais referenciados na amostra. E, a revisão bibliográfica em conjunto com outros processos de destaque como o levantamento histórico foi o método de pesquisa mais utilizado. Acerca do conceito de Diversidade Cultural as fundamentações mais recorrentes se fundam nos preceitos da UNESCO e da OMS.
\end{abstract}

Palavras-chave: Diversidade Cultural, Políticas Públicas, Audiovisual

\footnotetext{
${ }^{1}$ Universidade Estadual Paulista (Unesp), Bauru, Brasil, livia.redavi@outlook.com.br

${ }^{2}$ Universidade Estadual Paulista (Unesp), Bauru, Brasil, vlccomunicacao@gmail.com

${ }^{3}$ Universidade Estadual Paulista (Unesp), Bauru, Brasil, juliano.mauricio@unesp.br

${ }^{4}$ Universidade Estadual Paulista (Unesp), Bauru, Brasil, joao.darcadia@unesp.br
}

Abstract: This study is the result of a Scientific Initiation research funded by CNPq that aimed to identify and systematize theoretical and methodological frameworks of Brazilian intellectual production on Cultural Diversity in Public Policies for Audiovisual Communication for a period of ten years (from 2005 to 2015 ). The Integrative Review methodology was adopted. The sample selected for analysis were articles found in the annals of the annual national congress of the Sociedade Brasileira de Estudos Interdisciplinares da Comunicação (Intercom). The results indicated the authors Néstor García Canclini and César Bolaño as the most referenced authors in the sample. And, the literature review together with 
e-ISSN: 2317-675X | Comun. \& Inf., Goiânia, GO, v. 24, p. 1-13, 2021.

other prominent processes such as the historical survey was the most used research method. Regarding the concept of Cultural Diversity, the most recurrent foundations are based on UNESCO and WHO precepts.

Keywords: Cultural Diversity, Public Policy, Audiovisual

Resumen: Este estudio es el resultado de una investigación de Iniciación Científica financiada por el CNPq que tuvo como objetivo identificar y sistematizar los marcos teóricos y metodológicos de la producción intelectual brasileña sobre la Diversidad Cultural en las Políticas Públicas de Comunicación Audiovisual por un período de diez años (de 2005 a 2015). Se adoptó la metodología de Revisión Integrativa. La muestra seleccionada para el análisis fueron artículos encontrados en los anales del congreso nacional anual de la Sociedade Brasileira de Estudos Interdisciplinares da Comunicação (Intercom). Los resultados señalaron a los autores Néstor García Canclini y César Bolaño como los autores más referenciados de la muestra. Y, la revisión de la literatura junto con otros procesos destacados como el relevamiento histórico fue el método de investigación más utilizado. En cuanto al concepto de Diversidad Cultural, los fundamentos más recurrentes se basan en los preceptos de la UNESCO y la OMS.

Palabras clave: Diversidad Cultural, Políticas Públicas, Audiovisual

\section{INTRODUÇÃO}

Este estudo é uma síntese dos resultados do trabalho de iniciação científica financiado pelo CNPq "Matrizes teóricas e metodológicas da produção de conhecimento nacional acerca da Diversidade Cultural nas Políticas Públicas de Comunicação para Audiovisual” (2016/17). A relevância do projeto concerne a um entendimento mais profundo da situação da pesquisa brasileira no ramo das Políticas de Comunicação. Neste caso, o recorte estudado - a Diversidade Cultural - faz parte dos Direitos Culturais dos indivíduos, fundamentais para o desenvolvimento dos povos.

Haja vista que segundo o Decreto $n^{\circ}$ 6.177/2007 que estabeleceu a "Convenção Sobre a Proteção e Promoção da Diversidade das Expressões Culturais para o Brasil”, a diversidade cultural é compreendida como patrimônio comum da humanidade que deve ser valorizada e cultivada em benefício de todos. Assim, segundo o documento, este fator é fundamental para nutrir as capacidades e valores dos indivíduos, constituindo um dos principais motores do desenvolvimento sustentável das comunidades, povos e nações, sendo desejável para garantir paz e a segurança no plano local, nacional e internacional (BRASIL, 2007).

Além de ser compreendida também como fator de desenvolvimento social, inclusive econômico, a Diversidade Cultural está diretamente ligada à dignidade humana e suas 
e-ISSN: 2317-675X | Comun. \& Inf., Goiânia, GO, v. 24, p. 1-13, 2021.

liberdades fundamentais, estando relacionada com a Declaração Universal de Direitos Humanos e o Pacto Internacional de Direitos Econômicos, Sociais e Culturais.

Deste modo, este trabalho ensejou mapear as principais matrizes teóricas e metodológicas, a fim de melhor conhecer a situação da pesquisa nacional sobre a temática proposta. A metodologia utilizada foi a revisão integrativa que possibilitou a criação de um banco de dados com um total de 253 trabalhos sobre a temática contribuindo para o acervo do LECOTEC - Laboratório de Estudos em Comunicação, Tecnologia, Educação e Criatividade da UNESP - Bauru.

O material escolhido para análise neste estudo foram os artigos encontrados nos anais do congresso nacional anual da Sociedade Brasileira de Estudos Interdisciplinares da Comunicação (Intercom), levando em conta a relevância do evento para a pesquisa de comunicação no país.

\section{METODOLOGIA}

A metodologia selecionada foi a Revisão Integrativa, processo que tem por objetivo resumir a construção empírica e/ou teórica acerca de uma temática ou objeto. Segundo Botelho, Cunha e Mace (2011) esse método de pesquisa possibilita a produção de uma síntese do conhecimento de vários estudos já publicados, permitindo, assim, a geração de novos conhecimentos partindo dos resultados apresentados nas pesquisas antecedentes.

Souza, Silva e Carvalho (2010) lecionam que um Revisão Integrativa adequada deve seguir seis etapas bem definidas. As primeiras etapas consistem na identificação do tema e na escolha de critérios de exclusão e inclusão dos estudos a serem levantados, estas duas etapas foram realizadas no projeto de pesquisa "Diversidade Cultural nas Políticas de Comunicação para Audiovisual".

As demais etapas foram realizadas ao longo do desenvolvimento da pesquisa. O terceiro passo é o levantamento propriamente dito dos materiais. Os bancos de dados consultados foram: Portal de Periódicos Capes; Google Acadêmico; Repositório de artigos da Sociedade Brasileira de Estudos Interdisciplinares da Comunicação (Intercom); além dos repositórios e teses e dissertações dos programas de pós-graduação da área da Comunicação no Brasil.

Em seguida foi realizada a fase de categorização dos estudos selecionados. E para tanto, os autores Souza, Silva e Carvalho (2010) orientam que deve ser criado um instrumento elaborado capaz de ser aplicado a cada produção acadêmica analisada que possibilite 
e-ISSN: 2317-675X | Comun. \& Inf., Goiânia, GO, v. 24, p. 1-13, 2021.

identificar e sistematizar os dados relevantes da mesma. Essa ferramenta é denominada pelos autores como "Matriz de Síntese".

Assim, segundo as necessidades de nossa pesquisa o instrumento adequando a nossos objetivos foi elaborado. Nele constavam os seguintes tópicos: nome do artigo e do pesquisador, ano de publicação, instituição vinculada, metodologia empregada, bases teóricas empregadas e o último campo foi reservado para considerações do pesquisador.

Em seguida, ocorre a análise e interpretação dos resultados. Este passo para os autores Botelho, Cunha e Macedo (2011) é apontado como o momento de discussão sobre os textos levantados e sumarizados pela metodologia. Por fim, é apresentado o documento final da pesquisa que sintetiza o conhecimento levantado. Este documento, segundo os autores retrocitados deve apresentar os principais resultados obtidos pelo pesquisador juntamente com uma descrição detalhada e transparente de seu processo metodológico de pesquisa. O relatório final da pesquisa cumpriu tal finalidade e este trabalho é uma síntese do mesmo destacando suas principais contribuições.

\section{MATERIAL LEVANTADO E AMOSTRA}

Foi criado um banco de dados com o material encontrado na plataforma Zotero ferramenta dá a seus usuários a possibilidade de criação de bibliotecas públicas ou de uso restrito a seus membros. Neste banco de dados foram arquivados 31 teses, dissertações e trabalhos de conclusão de curso, 198 artigos acadêmicos e 24 livros e outros materiais. Totalizando 253 arquivos na íntegra.

A amostra selecionada para análise foi composta por artigos encontrados nos Anais do Congresso Nacional Anual da Sociedade Brasileira de Estudos Interdisciplinares da Comunicação (Intercom) entre os anos de 2005 e 2015. A escolha foi motivada tanto pela relevância do evento para a pesquisa de comunicação do país como a possibilidade de analisar materiais oriundos de todas as regiões do país.

Dos 34 artigos encontrados nos anais do congresso analisado, 7 foram excluídos após a leitura do conteúdo, pois não se adequaram a temática em questão. A exclusão foi feita com o auxílio da Matriz de Síntese, na etapa de sistematização do conhecimento levantado. Assim, os resultados aqui apresentados têm base os 27 artigos restantes. 
e-ISSN: 2317-675X | Comun. \& Inf., Goiânia, GO, v. 24, p. 1-13, 2021.

\section{RESULTADOS}

Ao final do processo metodológico identificamos que o pensamento do autor vinculado aos Estudos Culturais Néstor García Canclini foi a matriz teórica mais utilizada em nossa amostra. Dos 27 artigos analisados, 10 continham referências do autor. Sendo seus escritos mais utilizados como fundamentação teórica os seguintes livros: Culturas Híbridas (2006) e Consumidores e Cidadãos (2006).

O segundo autor mais citado foi César Bolaño (autor do ramo da Economia Política da Comunicação e Cultura), referenciado em 7 artigos. Sua produção mais referenciada foi Indústria Cultural, Informação e Capitalismo (2000), tendo os demais artigos referenciado outros escritos diversos.

Acerca do Conceito de Cultura e Diversidade Cultural verificamos que poucos são os artigos que conceituam diretamente o que é cultura e o que é diversidade cultural, apesar da vasta utilização destes termos. Em nossa análise percebemos duas linhas teóricas recorrentes nos estudos brasileiros da amostra analisada: a recorrência dos conceitos da Organização das Nações Unidas para a Educação, a Ciência e a Cultura (UNESCO) e da Organização Mundial da Cultura (OMC) para os dois tópicos e a teoria crítica e os estudos culturais.

A conceituação de Diversidade Cultural da UNESCO foi encontrada em 4 artigos, enquanto o conceito de Cultura da UNESCO em apenas 1. Apesar de aparentemente pouco expressiva, dada a variedade de autores utilizados nos demais artigos, cabe destacar essa recorrência. Ademais, foram citados 2 vezes o conceito de Exceção Cultural da OMC e o conceito de Cidadania Cultural.

Embora há uma variedade de autores que serviram de base teórica para os pesquisadores há tendências de escolas identificadas, sendo elas: a Teoria Crítica, os Estudos Culturais e a Economia Política da Comunicação. Tendo o conceito de Indústria Cultural sendo citado diretamente em 4 artigos.

Apenas 4 artigos se referiram diretamente a uma definição de cultura como base dos seus estudos e somente 3 artigos fazem o mesmo com a diversidade cultural. Todavia, dos 27 artigos analisados, 6 não tem possuem nenhuma fundamentação teórica sobre Cultura ou Diversidade Cultural, explicitamente ou implicitamente, embora tratem das políticas públicas culturais para a diversidade.

Contudo, mesmo sem conceituação explicita vários foram os autores que se fundaram nos preceitos da UNESCO e da OMC: 
e-ISSN: 2317-675X | Comun. \& Inf., Goiânia, GO, v. 24, p. 1-13, 2021.

Reis (2011) disserta sobre o surgimento de um debate na UNESCO nos anos 70 sobre um projeto de uma nova ordem mundial da informação e da comunicação. Esse movimento segundo a autora foi alavancado por países que questionavam a hegemonia dos Estados Unidos na comunicação e produtos culturais como o cinema.

A partir da década de 70, o silêncio em relação ao modelo de comunicação promovido pelo governo e pelos grandes grupos de mídia começa a se esgarçar, quando, na Unesco, surge um pioneiro debate sobre a democratização da comunicação, que resultou num projeto para uma "Nova ordem mundial da informação e da comunicação" (Nomic). Foi um movimento alavancado pelos países que questionavam a hegemonia norte-americana no campo da produção da comunicação por parte das agências de notícias, dos produtores cinematográficos e distribuidores de produtos culturais. A preocupação de então era com a necessidade de desenvolvimento de políticas nacionais de comunicação que dessem autonomia aos chamados países do Terceiro Mundo em oposição à centralidade dos chamados países imperialistas. (REIS, 2011, p. 7).

Nesse contexto surgia uma preocupação com a necessidade da criação de políticas nacionais voltadas a dar autonomia aos países dominados pela hegemonia cultural até então estabelecida. Não há conceituação de Diversidade Cultural ou Cultura.

A autora ainda disserta sobre o impacto do projeto Nomic no Brasil que mobilizou principalmente os profissionais de comunicação a instituições voltadas a questão da democratização da comunicação. Estes por outro lado enfrentaram grande oposição das grandes empresas de mídia do país. Reis assinala que este foi o primeiro momento em que se colocou formalmente a necessidade de uma nova política de comunicação na América Latina confrontando os governos militares estabelecidos na época.

Silveira (2015), usa como base o conceito de Cultura da Unesco e utiliza-se das considerações de Homero acerca da busca das necessidades culturais que passa inevitavelmente pela devida determinação do conceito de cultura encontrada no documento da UNESCO, a Declaração Universal sobre a Diversidade Cultural (2002).

Carvalho e Carvalho (2013), com base nos preceitos da UNESCO, classificam diversidade cultural como um direito humano. A plena fruição dos direitos culturais garante a diversidade fazendo com que qualquer indivíduo possa se expressar e criar sua obra e participar da vida cultural que escolher para si. De tal modo, os autores concluem que a diversidade cultural busca assegurar a liberdade de expressão e a paridade de acesso aos meios de difusão. 
e-ISSN: 2317-675X | Comun. \& Inf., Goiânia, GO, v. 24, p. 1-13, 2021.

Lopes (2013), segue Miguez ao colocar a diversidade cultural como patrimônio comum da humanidade tendo uma dupla natureza: simbólica e econômica. Miguez ainda comenta o documento da UNESCO de 2005 - Convenção sobre a Proteção e Promoção da Diversidade das Expressões Culturais - que garante o direito soberano dos Estados de implementarem políticas públicas para promover e proteger suas indústrias culturais, ou seja, o conceito de exceção cultural.

Em Bento (2007) é usado o conceito de Exceção Cultural da Organização Mundial da Cultura. Segundo esse conceito a exceção cultural é uma forma de legitimar formas de intervenção regulatória e financeira dos poderes públicos a fim de corrigir distorções internacionais da economia de mercado no campo da cultura e da comunicação. Não há conceituação de Diversidade Cultural ou Cultura. Moreira (2014), destaca dois documentos: Convenção sobre a Proteção e a Promoção da Diversidade das Expressões Culturais de 2005 da UNESCO e a Declaración Conjunta sobre Diversidad en la Radiodifusión de 2007 da Organização dos Estados Americanos (OEA) que, segundo ela, ainda são válidos para o contexto sul-americano.

Uma outra linha de raciocínio encontrada foram os autores que se fundaram nos conceitos de Indústria Cultural e na Escola dos Estudos Culturais:

Bundt (2007) se baseia nos conceitos de Indústria Cultural para explicar as mudanças ocorridas na economia mundial que influenciaram no continente latino-americano e acabaram por alterar o papel do Estado que mudou sua atuação na promoção e divulgação das Indústrias Culturais de seus países. Assim sendo, o autor assinala que o filme passa a ser visto como um produto. Não há conceituação de Diversidade Cultural ou Cultura.

Na mesma linha também Mota (2010) baseia sua reflexão citando o conceito de Indústria Cultural de Theodor Adorno e Max Horkheimer e a completando com os apontamentos de Bolaño, especificamente a organização do modelo capitalista de organização industrial que controla a cultura e a disseminação da informação que se opõe a sociedade (que não pode reagir), e o fenômeno da reestruturação capitalista, marco que modifica as relações econômicas e aumenta a assimetria e a exclusão. Não há conceituação de Diversidade Cultural e Cultura. Morais (2014), funda-se na noção de Indústria Cultural e seus efeitos econômicos e de dominação. Destacando o feito mercantil predados das relações historicamente construídas e da fragilidade fruto da carência de distribuição de renda e educação de qualidade.

Já Silva (2014), problematiza o conceito de cultura e sua origem etimológica que se refere ao ato de cultivar, posteriormente sendo associada a formação intelectual no 
e-ISSN: 2317-675X | Comun. \& Inf., Goiânia, GO, v. 24, p. 1-13, 2021.

Iluminismo (educação e a razão) que levaria ao progresso. Contudo, no século XIX a antropologia alarga o conceito incluindo além do conhecimento, a crença, os hábitos, costumes, a arte...

Silva (2014) ainda assinala que os Estudos Culturais carregam um olhar mais pluralista de cultura. Segundo Hall, o papel dos Estudos Culturais é reconhecer o papel da cultura na determinação e compressão de todas as instituições e relações sociais. Levando em conta que numa perspectiva crítica, atribui-se um valor elevado à cultura hegemônica comparada à cultura dos oprimidos, do mesmo modo uma forma reducionista de compreensão do conceito.

Rocha (2015) utiliza-se do conceito de cultura de Raymond Williams, autor dos Estudos Culturais, que defende que a cultura é de todos para todos, diferente da ideia antiga que via a cultura como um privilégio de uma elite educada.

Além disso, por vezes cultura é relacionada com a ideia de cidadania:

Canuto (2013) disserta com base em Cortina sobre o conceito de Cidadania Cultural. Este tipo de cidadania seria o vínculo fundamental entre grupos sociais diversos. $\mathrm{O}$ autor ainda assinala que as artes e a cultura são bens reivindicados pela sociedade e os movimentos artístico-sociais buscam uma democratização do acesso à bens culturais fomentando a cidadania cultural e permitindo as minorias manifestar a sua identidade em canais paralelos à mídia tradicional.

Borges (2014), assinala a importância cultural e social da produção audiovisual, sendo essencial para a construção de uma identidade cultural e também a expressão da cidadania por meio de diversos canais como a televisão, o vídeo e o cinema.

Além disso foram encontradas considerações acerca das relações econômicas envolvendo a cultura:

Rodrigues, Santos e Pereira (2015) assinalam o papel da cultura como produto mercadológico que além de divulgar os valores de uma determinada marca ainda promovem a homogeneidade nas formas de linguagem de uma dada expressão artística.

Já Cesário (2008) parte de Getino Silva para problematizar o conceito de cultura assinalando que cultura também é sua produção, comercialização, investimento, exportações e emprego. Não há conceituação de Diversidade Cultural.

E, Santos (2008) cita autor Andrew Calabrese e seu pensamento de que nenhuma concepção de cultura no mundo moderno é completa se não levar em conta o papel ocupado pela indústria de mídia, como intuição e tecnologia de comunicação e informação. Não há conceituação de Diversidade Cultural. 
e-ISSN: 2317-675X | Comun. \& Inf., Goiânia, GO, v. 24, p. 1-13, 2021.

Ainda foram utilizados Marilena Chauí, Canclini e seu conceito de Comunidades Transnacionais juntamente com Ortiz e seu conceito de Cultura Internacional Popular e ainda a noção de Pluralidade por:

No artigo de Lima (2006) é usado o conceito de Cultura de Marilena Chauí que descreve cultura em sentido lato como um conjunto de práticas, ideias e sentimentos que exprimem as relações simbólicas dos homens com a realidade e em sentido mais estrito ela se remete às produções artísticas e intelectuais propriamente ditas. Não há conceituação de Diversidade Cultural.

Mendes (2008) se baseia em Canclini seu conceito de Comunidades Transnacionais de consumidores, na qual, uma única cultura estabelece sua hegemonia através de produtos de consumo. Além disso há a referência do conceito de Cultura Internacional Popular de Renato Ortiz. Não há conceituação de Diversidade Cultural ou Cultura.

Já Paiva (2008) cita a noção da pluralidade das sociedades tanto na programação quando nos conselhos diretores, o papel cultural da programação, a conscientização política, o acesso universal, a independência e atenção a minorias das televisões públicas. Não há conceituação de Diversidade Cultural ou Cultura.

Há ainda os autores que não conceituam implicitamente ou explicitamente Cultura, Diversidade Cultural ou conceitos correlatos, exemplo: Hibridismo Cultural e Cultura Internacional Popular - (AGUIAR, 2011; ALENCAR, 2014; LIEDTKE; FERREIRA; LIMA; PARENTE, 2015; RELVA, 2015; TIMES, 2013; XAVIER, 2014).

Por fim, a metodologia mais utilizada é a Revisão Bibliográfica, presentes em 19 dos 27 artigos analisados, foi aplicada mesmo em conjunto com outras metodologias diversas como: a Análise de Legislação (9 artigos), a Análise de Dados (6 artigos), o Levantamento Histórico (6 artigos), o Estudo de Caso (6 artigos) e o Estudo Comparado (6 artigos). Também foram encontrados em números menos relevantes os métodos como Coleta de Dados (3 artigos), Estudo de Mercado (2 artigos) e Entrevistas (1 artigo).

\section{CONSIDERAÇÕES FINAIS}

Percebemos o destaque da metodologia Revisão Bibliográfica em conjunto com outros processos como a Revisão Histórica como uma demonstração da busca do pesquisador nacional por entender a atual situação do Brasil no ramo das políticas públicas do audiovisual a partir de um olhar histórico. E, complementando esta tendência o uso de outras metodologias, como a análise de dados e estudo de caso também apontam para a preocupação 
e-ISSN: 2317-675X | Comun. \& Inf., Goiânia, GO, v. 24, p. 1-13, 2021.

em compreender os efeitos e resultados das medidas tomadas pelo governo ao longo do tempo.

A partir disto, concluímos que a pesquisa nacional está mais inclinada para a compressão do que já foi feito, do que para o estudo de novas possibilidades de atuação governamental no setor. Embora, vários artigos sejam prescritivos em se tratando do que “deve ser” uma política pública ideal, as prescrições levantadas são mais princípios gerais para aplicação de políticas concretas, do que propostas elaboradas em si. Isso está em consonância com os dois autores mais citados na amostra, Nestor Garcia Canclini e César Bolaño.

Uma vez que, estes dois autores possuem uma característica em comum: seus escritos serem considerados textos base para compreender não só o cenário político que envolve a comunicação e a cultura, mas também o que se deve esperar das políticas públicas. Assim, o uso destes autores nos artigos analisados para prescrever o que é uma boa política cultural é comum.

Em se tratando do conceito de Diversidade Cultural e Cultura em si, foi identificada em nosso estudo uma tendência do uso de documentos internacionais da UNESCO e da OMC como um norte para analisar as medidas tomadas pelo governo brasileiro ao longo do tempo. Contudo, em geral, fala-se de Diversidade Cultural, mas não há apontamentos ou desdobramentos em busca de defini-la ou mensurá-la. Por vezes, os autores utilizam como fundamentação fontes diversas em seus estudos e em geral, fala-se de Diversidade Cultural, mas não há apontamentos ou desdobramentos em busca de defini-la ou mensurá-la.

Como em Lima (2006) foi usado o conceito de cultura de Marilena Chaú, a importância do que é cultura conceitualmente é levantada por diversas ocasiões. Embora, raramente está temática seja aprofundada. Uma hipótese do que elevou a falta desta densidade conceitual foi a limitação do número de páginas por estudo da amostra analisada (15 páginas por autor - limite dado pelo Congresso Intercom).

Em suma, as metodologias mais utilizadas e os dois autores mais citados complementam o quadro apresentado pela ausência ou precária conceituação do que é a Diversidade Cultural, embora sua importância seja reconhecida. Assim, a pesquisa brasileira acerca da Diversidade Cultural nas Políticas de Comunicação para Audiovisual preocupa-se mais em entender os resultados e efeitos das políticas aplicadas ao longo da história do país e está mais concentrada em prescrições de princípios gerais de aplicação das políticas culturais do que a proposição de medidas concretas. 


\section{REFERÊNCIAS}

ALENCAR, J. F. Geografia, comunicação e cultura: a comunicação na desglobalização. In: CONGRESSO BRASILEIRO DE CIÊNCIAS DA COMUNICAÇÃO, 37., 2014, Foz do Iguaçu, PR. Anais [...]. Foz do Iguaçu, PR: Intercom, 2014. Disponível em:

http://www.intercom.org.br/papers/nacionais/2014/resumos/R9-0641-1.pdf. Acesso em: 7 jul. 2017.

BENTO, G. R. Políticas públicas para o intercâmbio audiovisual na América Latina. In: CONGRESSO BRASILEIRO DE CIÊNCIAS DA COMUNICAÇÃO, 30., 2007, Santos, SP. Anais [...]. Santos, SP: Intercom, 2007. Disponível em: http://www.intercom.org.br/papers/nacionais/2007/resumos/R1223-1.pdf. Acesso em: 7 jul. 2017.

BORGES, D. S. A produção cinematográfica brasileira (1995-2013) e o atual modelo de políticas públicas para o cinema nacional. In: CONGRESSO BRASILEIRO DE CIÊNCIAS DA COMUNICAÇÃO, 37., 2014, Foz do Iguaçu, PR. Anais [...]. Foz do Iguaçu, PR: Intercom, 2014. Disponível em: http://www.intercom.org.br/papers/nacionais/2014/resumos/R9-0694-1.pdf. Acesso em: 7 jul. 2017.

BRASIL. Decreto $\mathbf{n}^{0}$ 6.177, de $\mathbf{1}^{\circ}$ de agosto de 2007. Promulga a Convenção sobre a Proteção e Promoção da Diversidade das Expressões Culturais, assinada em Paris, em 20 de outubro de 2005. Brasília: Presidência da República, 2007. Disponível em: http://www.planalto.gov.br/ccivil_03/_ato2007-2010/2007/decreto/d6177.htm. Acesso em: 7 jul. 2017.

BUNDT, R. Os modelos de fomento ao cinema no Brasil e Argentina. . In: COLÓQUIO BRASIL-ARGENTINA DE CIÊNCIAS DA COMUNICAÇÃO, 1., 2007, Santos, SP. Anais [...]. Santos, SP: UNISANTOS, 2007. Disponível em:

http://www.intercom.org.br/papers/nacionais/2007/resumos/R1685-1.pdf. Acesso em: 7 jul. 2017.

CANUTO, K. J. O audiovisual paraibano enquanto elemento promotor de cidadania cultural. In: CONGRESSO BRASILEIRO DE CIÊNCIAS DA COMUNICAÇÃO, 36., 2013, Manaus. Anais [...]. Manaus: Intercom, 2013. Disponível em: http://www.intercom.org.br/papers/nacionais/2013/resumos/R8-1779-1.pdf. Acesso em: 7 jul. 2017.

CARVALHO, J. M.; CARVALHO, A. M. G. Diversidade cultural na pauta das indústrias criativas no Brasil. In: CONGRESSO BRASILEIRO DE CIÊNCIAS DA COMUNICAÇÃO, 36., 2013, Manaus. Anais [...]. Manaus: Intercom, 2013. Disponível:

http://www.intercom.org.br/papers/nacionais/2013/resumos/R8-1540-1.pdf. Acesso em: 7 jul. 2017.

CESÁRIO, Lia Bahia. O debate contemporâneo sobre as leis e políticas públicas do audiovisual no Brasil. In: CONGRESSO BRASILEIRO DE CIÊNCIAS DA

COMUNICAÇÃO, 30., 2007, Santos, SP. Anais [...]. Santos, SP: Intercom, 2007. Disponível em: http://www.intercom.org.br/papers/nacionais/2007/resumos/R1817-1.pdf. Acesso em: 07 jul. 2017. 
FERREIRA, R. G. S.; LIMA, A. N. G.; PARENTE, T. C. Audiovisual em foco: das políticas públicas às implementações. In: CONGRESSO BRASILEIRO DE CIÊNCIAS DA COMUNICAÇÃO, 38., 2015, Rio de Janeiro. Anais [...].Rio de Janeiro: Intercom, 2015. Disponível em: http://portalintercom.org.br/anais/nacional2015/resumos/R10-3121-1.pdf. Acesso em: 7 jul. 2017.

LIEDTKE, P. F.; AGUIAR, I. Políticas públicas de comunicação no governo lula (20032010): avanços e retrocessos rumo à democratização do setor. In: CONGRESSO BRASILEIRO DE CIÊNCIAS DA COMUNICAÇÃO, 34., 2011, Recife. Anais [...]. Recife: Intercom, 2011. Disponível em:

http://www.intercom.org.br/papers/nacionais/2011/resumos/R6-0897-1.pdf. Acesso em: 7 jul. 2017.

LIMA, T. M. O. A experiência da lei de incentivo à cultura do Rio Grande do Sul e suas implicações. In: CONGRESSO BRASILEIRO DE CIÊNCIAS DA COMUNICAÇÃO, 29. 2006, Brasília. Anais [...]. Brasília: Intercom, 2006. Disponível em: http://www.intercom.org.br/papers/nacionais/2006/resumos/R0747-1.pdf. Acesso em: 7 jul. 2017.

LOPES, R. S. Cultura e desenvolvimento: a serviço de quem? In: CONGRESSO BRASILEIRO DE CIÊNCIAS DA COMUNICAÇÃO, 34., 2013, Manaus. Anais [...]. Manaus: Intercom, 2013. Disponível em: http://www.intercom.org.br/papers/nacionais/2013/resumos/R8-0080-2.pdf. Acesso em: 7 jul. 2017.

MENDES, T. Distribuição cinematográfica: uma revisão bibliográfica do global ao local. In: CONGRESSO BRASILEIRO DE CIÊNCIAS DA COMUNICAÇÃO, 31., 2008, Natal, RN. Anais [...]. Natal, RN: Intercom, 2008. Disponível em: http://www.intercom.org.br/papers/nacionais/2008/resumos/R3-0550-1.pdf. Acesso em: 7 jul. 2017.

MOREIRA, S. V. Indústria de mídia e diversidade na América do Sul (2009-2013). 2014. In: CONGRESSO BRASILEIRO DE CIÊNCIAS DA COMUNICAÇÃO, 37., 2014, Foz do Iguaçu, PR. Anais [...].Iguaçu, PR: Intercom, 2014. Disponível em: http://geografias.net.br/papers/2014/R9-0285-1.pdf. Acesso em: 7 jul. 2017.

MORAIS, O. J. A produção de novas teorias: crítica (in)voluntária mas indispensável à servidão voluntária do pensamento comunicacional da américa latina e de sua trajetória histórico-cultural. In: CONGRESSO BRASILEIRO DE CIÊNCIAS DA COMUNICAÇÃO, 37., 2014, Foz do Iguaçu, PR. Anais [...].Iguaçu, PR: Intercom, 2014. Disponível em: http://www.intercom.org.br/papers/nacionais/2014/resumos/R9-0672-2.pdf. Acesso em: 07 jul. 2017.

MOTA, J. Políticas culturais no Brasil: o minc e o desafio de implantar um plano nacional de cultura. In: CONGRESSO BRASILEIRO DE CIÊNCIAS DA COMUNICAÇÃO, 33., 2010, Caxias do Sul, RS. Anais [...].Caxias do Sul, RS: Intercom, 2010. Disponível em: http://www.intercom.org.br/papers/nacionais/2010/resumos/R5-3112-1.pdf. Acesso em: 07 jul. 2017. 
PAIVA, T. S. B. TV Brasil: análise de uma TV em crise de identidade. In: CONGRESSO BRASILEIRO DE CIÊNCIAS DA COMUNICAÇÃO, 34., 2008, Natal, RN. Anais [...]. Natal, RN: Intercom, 2008. Disponível em:

http://www.intercom.org.br/papers/nacionais/2008/resumos/R3-0550-1.pdf. Acesso em: 7 jul. 2017.

REIS, R. Lutas sociais pela democratização da comunicação e comunicação pública: biografias de dois mundos paralelos e seus pontos de convergências. In: CONGRESSO BRASILEIRO DE CIÊNCIAS DA COMUNICAÇÃO, 34., 2011, Recife. Anais [...]. Recife: Intercom, 2011. Disponível em:

http://www.intercom.org.br/papers/nacionais/2011/resumos/R6-2926-1.pdf. Acesso em: 07 jul. 2017.

RELVA, C. Os projetos de cooperação audiovisual Na América Latina: DOCTV América Latina e Televisão América Latina (TAL) como experiências de interculturalidade.

Disponível em: http://portalintercom.org.br/anais/nacional2015/resumos/R10-3656-1.pdf. Acesso em: 7 jul. 2017.

ROCHA, F. P. Coprodução cinematográfica internacional no brasil e na argentina (20052014): um estudo comparado. In: CONGRESSO BRASILEIRO DE CIÊNCIAS DA COMUNICAÇÃO, 34., 2015, Rio de Janeiro. Anais [...]. Rio de Janeiro: Intercom, 2015. Disponível em: http://portalintercom.org.br/anais/nacional2015/resumos/R10-1517-2.pdf. Acesso em: 7 jul. 2017.

RODRIGUES, C. J.; SANTOS, L.; PEREIRA, D. A lei Murilo Mendes e a promoção da diversidade cinematográfica. . In: CONGRESSO BRASILEIRO DE CIÊNCIAS DA COMUNICAÇÃO, 34., 2015, Rio de Janeiro. Anais [...]. Rio de Janeiro: Intercom, 2015. Disponível em: http://portalintercom.org.br/anais/nacional2015/resumos/R10-2254-1.pdf. Acesso em: 7 jul. 2017.

SANTOS, Suzy dos. VIEIRA, Taynée Mendes. PAIVA, Thais da Silva Brito de. Condições de diversidade na distribuição e na produção audiovisual: análise dos casos da televisão comercial aberta, da distribuição cinematográfica e da criação de uma rede pública de televisão. In: CONGRESSO BRASILEIRO DE CIÊNCIAS DA COMUNICAÇÃO, 31. 2008, Natal, RN. Anais [...]. Natal, RN: Intercom, 2008. Disponível em:

http://www.intercom.org.br/papers/nacionais/2008/resumos/R3-0550-1.pdf. Acesso em: 07 jul. 2017.

SILVA, Priscila Kalinke da. Considerações históricas e teóricas dos estudos culturais e aproximações com os estudos em comunicação. In: CONGRESSO BRASILEIRO DE CIÊNCIAS DA COMUNICAÇÃO, 37., 2014, Foz do Iguaçu, RS. Anais [...].Foz do Iguaçu, RS: Intercom, 2014. Disponível em:

http://www.intercom.org.br/papers/nacionais/2014/resumos/R9-2111-1.pdf. Acesso em: 7 jul. 2017.

SILVEIRA, Alberto Magno Perdigão. Comunicação pública como condição à diversidade cultural: uma revisão bibliográfica na perspectiva de uma nova cultura política. In: CONGRESSO BRASILEIRO DE CIÊNCIAS DA COMUNICAÇÃO, 34., 2015, Rio de Janeiro. Anais [...]. Rio de Janeiro: Intercom, 2015. Disponível em: 
e-ISSN: 2317-675X | Comun. \& Inf., Goiânia, GO, v. 24, p. 1-13, 2021.

http://portalintercom.org.br/anais/nacional2015/resumos/R10-2628-1.pdf. Acesso em: 7 jul. 2017.

TIMES, Milena. Políticas públicas do audiovisual no Brasil: formação e desafios. In:

CONGRESSO BRASILEIRO DE CIÊNCIAS DA COMUNICAÇẪO, 36., 2013, Manaus.

Anais [...]. Manaus: Intercom, 2013. Disponível em:

http://www.intercom.org.br/papers/nacionais/2013/resumos/R8-1462-1.pdf. Acesso em: 7 jul. 2017.

XAVIER, Renan Schlup. Percebendo a América Latina para a construção da pesquisa no campo da comunicação - uma reflexão sobre o passado, sua influência sobre o presente e apontamentos para um futuro democrático. In: CONGRESSO BRASILEIRO DE CIÊNCIAS DA COMUNICAÇÃO, 37., 2014, Foz do Iguaçu, PR. Anais [...].Foz do Iguaçu, PR:

Intercom, 2014. Disponível em:

http://www.intercom.org.br/papers/nacionais/2014/resumos/R9-2346-1.pdf. Acesso em: 7 jul. 2017. 